\title{
Digital twin technology as a modern approach to quality management
}

\author{
Nikita Rodionov ${ }^{1 *}$ and Lyudmila Tatarnikova ${ }^{1}$ \\ ${ }^{1}$ Irkutsk National Research Technical University, 664074, Lermontova str., 83, Irkutsk, Russia
}

\begin{abstract}
The concept of a digital twin and its types are discussed in this paper. The essence of the development of digital twins in the SysML language, the use of AnyLogic (simulation software) and the use of MES (Manufacturing Execution Systems) software for communication with production systems are described. The functions of neural technologies that can be integrated into a modern QMS (quality management system) are considered. The use of digital twins in the quality management system allows monitoring inconsistencies in the technological component of production and quickly eliminating them, and also offers solutions to the identified problem. Companies are now finding a competitive advantage in digital technologies, especially digital twins, whose economic benefits are undeniable. The quality management system of enterprises with high-tech industries is more and more moving into the analysis of big data and in interaction with the digital environment. Thus, it is so important to pay attention to technologies directly related to the analysis of the quality of the product and the processes of its creation. As a result of the study, a clear connection between advanced information technologies and the development of the quality management system of enterprises was revealed.
\end{abstract}

\section{Introduction}

Nowadays, the economy of a new technological generation is actively developing - the digital economy, which is largely determined by Smart Big Data. The central place in the economy is occupied by the sphere of material production, i.e. a high-tech industry that must meet the requirements of global competitiveness, efficiency and high labor productivity. For the best fulfillment of the quality plan, meeting customer expectations and maintaining production at a high level, leading companies are rapidly developing the digital transformation of their production into high-tech one. [6]

Today, the industry is developing digital platforms, for example, digital twins of real objects, products and production. Systems of intelligent assistants are developing, global automation, robotization and intellectualization of industry are taking place, and the transition to cyber-physical systems is under way. These global technological changes are accompanied by the development of fundamentally new business processes and business models at all levels. [1.5]

\footnotetext{
* Corresponding author: nikrodionov411@gmail.com
} 
A digital twin is a virtual prototype of a physical object or group of objects that is designed to simulate their behavior. Virtual models can determine the state of physical objects, as well as predict, assess and analyze changes. [2]

A high level of digital twin means that this technology must provide a difference between the results of virtual and physical tests within $\pm 5 \%$ (in this case, it has the right to be called a digital twin, otherwise the technology remains an electronic model, digital mock-up, digital prototype, etc.), which are created within the framework of traditional iterative software development, i.e. within the framework of software development in small stages, during which the obtained intermediate results are analyzed, new requirements are put forward, and the previous stages of work are corrected. [8]

The digital twin answers the questions: "Where to measure?" and "What to measure?", i.e. it is necessary to indicate critical areas in which sensors and critical characteristics should be placed, for example, deformations, temperature, pressure, vibration displacement, vibration acceleration, and others. Then you should indicate the path of data storage, processing, transmission and protection (Big Data).

The digital twin shifts the focus to the process of generating meaningful data, during which intelligent big data is generated. Moreover, the digital twin makes it possible not only to adequately describe the behavior of a real object or product in all modes of operation (including normal operating conditions, violations of these conditions, emergency situations, etc.), but also to simulate various possible situations with a high degree of accuracy (including their various combinations and overlays). Thus, the digital twin has predictive potential, in contrast to a simple set of sensors, which only help to generate data on processes that have already taken place and does not allow predictions of complex phenomena and situations. $[2,7,4]$

It is fundamentally important to distinguish digital twins from digital shadows, which are systems of connections and dependencies that approximately describe the behavior of a real object or product under certain conditions of its operation, but are not able to simulate situations in which the object was not used. The digital twin provides real-time monitoring of systems and processes, as well as timely data analysis to prevent problems before they occur, plan preventive maintenance, reduce or prevent downtime, add new features, plan for future updates and new developments.

Also, the automatic analysis of big data using the artificial intelligence of the digital twin will provide options for more accurate calculation of various situations and tasks in production, which will have a positive effect on the final product, and for optimizing the main aspects of the product life cycle. At the same time, digital twin technology makes it possible to reduce the cost of system verification and testing. [1]

The functionality of this technology allows the company's quality management system to respond to the current requirements of high-tech production and timely improve the production process or the product itself if it has its own digital twin.

The use of technology reduces the company's overall product development costs. (Figure 1) $[13]$. 


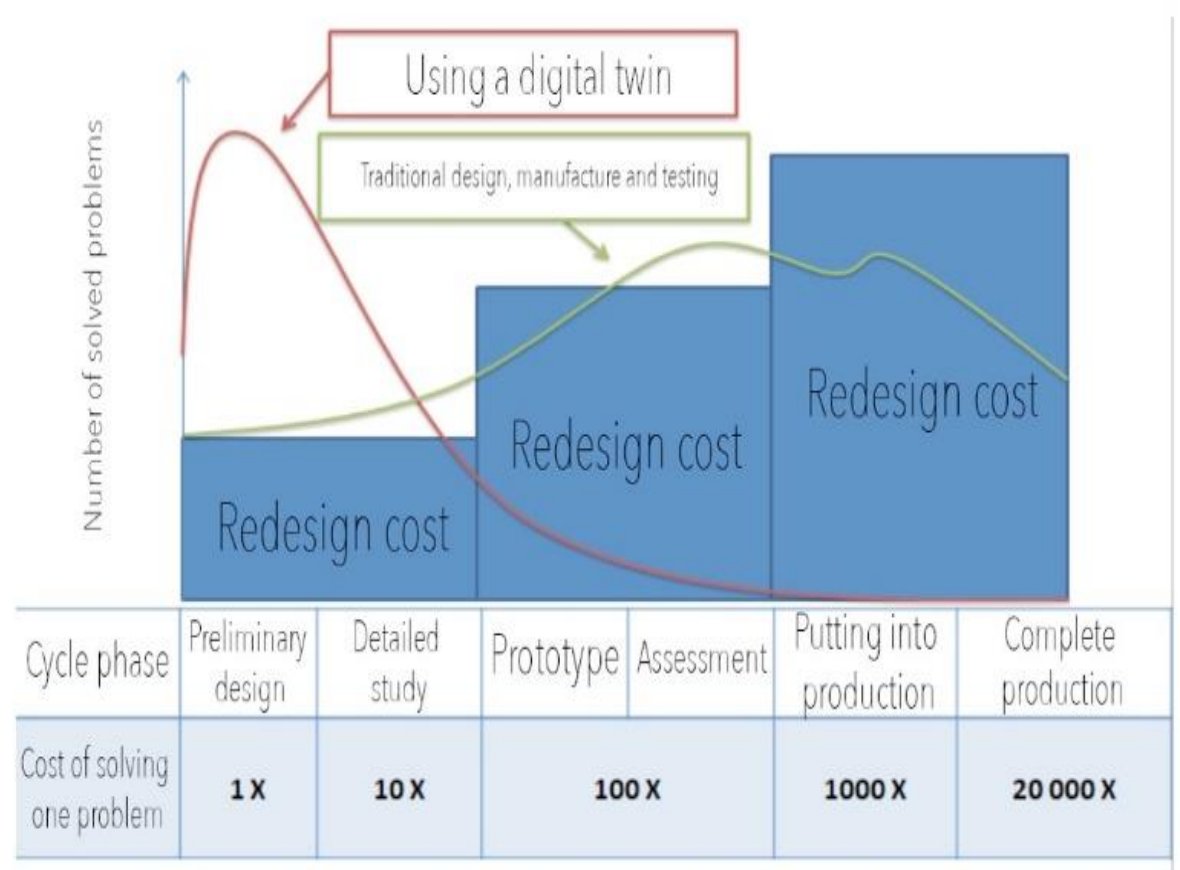

Fig. 1. Redesign cost using a digital twin.

\section{Types of digital twins}

The digital twin of a product combines digital modeling and system-oriented product development processes. It enables you to design, simulate and validate complex products, automate the design of electrical and electronic components, and manage software code without the need for physical prototypes. [9]

Modeling, simulation and optimization of production processes in a digital environment with the possibility of automated code generation for programmable logic controllers (PLCs) form the digital twin of production.

As a result of the joint modeling of mechatronics (mechatronics is a field of science and technology based on the synergistic combination of precision mechanics units with electronic, electrical and computer components that ensure the design and production of qualitatively new mechanisms, machines and systems with intelligent control) and industrial automation, an integral model is formed, which serves as the basis for the virtual commissioning of production processes.

The optimal sequence of operations is planned based on the availability of the production facility and possible constraints. Automatically generated work instructions, technical and safety information, and other required documents are available for employees in production facilities in a digital form. The system quickly responds to deviations in process targets, enabling the transition to predictive planning. This is made possible by networked products and solutions for automation, industrial communication and security.

Process digital twins are created based on the design of an optimal technological process. These models are then compared with the actual process parameters in real time, obtained from the automated process control system (APCS) or from data archives.

The same concept is used in the case of Advanced Process Control (APC) systems, where the optimal production parameters of the APC system are compared with the real ones. The 
difference between optimal parameters and actual ones is the potential of the opportunities for the operation of the enterprise.

\section{Planning of the production process}

The entire production process can be planned and developed in the virtual world. Here, product and component data are connected to available manufacturing operations, equipment, tools, and other required resources, including supplier resources throughout the value chain. Even assembly operations can be modeled to optimize robot trajectories and provide ergonomic workspaces for personnel to reduce the risk of injury. [10]

Continuous improvement and optimization of the material flow in production is essential for production planning. Simulation modeling of the latter allows one to quickly detect bottlenecks, increase their throughput, optimize energy consumption of the entire production cycle of the enterprise, prioritize and determine the directions in which the situation can be improved in order to avoid disruptions and instability of production, excessive consumption of raw materials and energy resources.

\section{Development of digital twins}

SysML is a general-purpose graphical modeling language that supports the analysis, specification, design, and validation of complex systems. SysML includes 9 diagrams: package diagram, requirement diagram, action diagram, sequence diagram, state diagram, use case diagram, internal block diagram, and parametric diagram.

SysML can be used at any level of system detail and helps engineers focus on design rather than the traditional hierarchical complexity of documents and drawings. [3]

One of the recognized tools for implementing a simulation model as part of creating a digital twin is AnyLogic, a powerful and flexible simulation environment. MES-system is designed for modeling and control of intrashop material flows in the dispatch control loop. A modern MES system is designed to work with both modern IoT (Internet of Things) interfaces and legacy hardware, which makes it possible to endow huge amounts of data with usefulness and consistency. [7]

In this case, the MES system acts as an intermediate layer of the translator, which turns the data flow into valuable information suitable for making strategic decisions.

\section{Conclusions}

According to the Digital Twin Market report, the global digital twin market, estimated at $\$$ 3.1 billion in 2020 , is projected to reach $\$ 48.2$ billion by 2026 . [11]

It is possible to increase the level of management decisions made on the basis of the provided digital analytics by integrating information from different expert systems into a single and well-protected database. Integration of digital twins of equipment and process seems to be the most urgent today. Such a combination also opens up new opportunities for increasing the productivity and profitability of enterprises, and the quality of products.

Nowadays, many companies are engaged in methodological issues of building digital twins: determining a set of controlled parameters (signals), their classification, etc.

Further research in the field of digital twins should be aimed at organizing communication between a real industrial facility and its digital model, i.e. the exchange of signals between real and virtual controllers.

Thus, the modern approach to quality management is increasingly becoming a digital version of the quality management system, which is driven by artificial intelligence. 


\section{References}

1. A.I. Borovkov, Yu.A. Ryabov, V.M. Maruseva, Digital production: methods, ecosystems, technologies, p. 24-44 (2018) URL: http://assets.fea.ru/ (date of access: 07.09.2020)

2. D.S. Kokorev, N.P. Posmakov, Colloquium-journal, 26 (50) (2019) URL: https://cyberleninka.ru/article/n/primenenie-tsifrovyh-dvoynikov-v-proizvodstvennyhprotsessah (date of access: 09.09.2020)

3. V.V. Makarov, E.B. Frolov, I.S. Parshina, M.V. Ushakova, The concept of developing a digital twin, V.A. Trapeznikov Institute of Control Problems of RAS, Russia (Moscow, 2019) URL: https://mlsd2019.ipu.ru/proceedings_1/section_15/12521254.pdf (date of access: 09.09.2020)

4. N.V. Kurganova, M.A. Filin, D.S. Chernyaev, A.G. Shaklein, D.Ye. Namiot, International Journal of Open Information Technologies, 5 (2019) URL: https://cyberleninka.ru/article/n/vnedrenie-tsifrovyh-dvoynikov-kak-odno-izklyuchevyh-napravleniy-tsifrovizatsii-proizvodstva (date of access: 08.09.2020)

5. E.B. Frolov, I.S. Parshina, A.S. Zaitsev, A.S. Klimov, Science-intensive technologies in mechanical engineering, 2 (92), 42-48 (2019)

6. A.V. Guryanov, D.A. Zakoldaev, A.V. Shukalov, I.O. Zharinov, M.O. Kostishin, Scientific and technical bulletin of information technologies, mechanics and optics, $\mathbf{1 8}$, 2, 268-277 (2018)

7. S.A. Sinyagov, V.P. Kupriyanovskiy, P.V. Kurenkov, D.E. Namiot, A.V. Stepanenko, et al, International Journal of Open Information Technologies, 5, 5, 46-79 (2017)

8. A.P. Dobrynin, K.Yu. Chernykh, V.P. Kupriyanovsky, P.V. Kupriyanovsky, S.A. Sinyagov, International Journal of Open Information Technologies, 4, 1, 4-11 (2016)

9. Iterative software development. [Electronic resource] - URL: https://webcreator.ru/articles/iterative_development (date of access: 02.09.2020)

10. N.A. Demkovich, I.A. Volkov, E.I. Yablochnikov, Bulletin of the Samara Scientific Center of the Russian Academy of Sciences, 18, 3-4, 459-463 (2016)

11. A. Gulli, S. Pal, Keras Library - a deep learning tool (DMK Press, 2017)

12. Digital Twin Market worth $\$ 48.2$ billion by 2026 . [Electronic resource] - URL: https://www.marketsandmarkets.com/PressReleases/digital-twin.asp (date of access: 05.09.2020)

13. D.S. Kokorev, A.A. Yurin, Colloquium-journal, 10 (34) (2019) URL: https://cyberleninka.ru/article/n/tsifrovye-dvoyniki-ponyatie-tipy-i-preimuschestvadlya-biznesa (date of access: 06.09.2020) 